\title{
Imaging and Minimally Invasive Biopsy for Postmortem Pulmonary Fat Embolism Diagnosis
}

\author{
Liauw Djai Yen, ${ }^{1}$ Clara Valentia, ${ }^{2}$ Gabriella, ${ }^{3}$ Mutiara Jesslyn Taslim, ${ }^{3}$ Leonardo, ${ }^{3}$ Florentina Reddy, ${ }^{3}$ \\ Oscar Odillo Laman, ${ }^{3}$ Maria Zita ${ }^{3}$ \\ ${ }^{1}$ Department of Forensic and Medicolegal, Faculty of Medicine and Health Sciences, Krida Wacana Christian \\ University, Jakarta, Indonesia, ${ }^{2}$ Department of Anesthesiology, Faculty of Medicine and Health Sciences, \\ Krida Wacana Christian University, Jakarta, Indonesia, ${ }^{3}$ Faculty of Medicine, Atma Jaya Catholic
} University of Indonesia, Jakarta, Indonesia

\begin{abstract}
In recent years, imaging technologies and minimally invasive biopsy have been gaining importance in forensic settings. This study aimed to evaluate the role of imaging and minimally invasive biopsy in postmortem diagnosis of pulmonary fat embolism. This was a systematic literature review by using Pubmed, EBSCO-Host, and ProQuest to search for studies on postmortem diagnosis of pulmonary fat embolism with postmortem imaging and minimally invasive biopsy. Five studies were included in the systematic review. These studies employed the following diagnostic technics: postmortem computed tomography (PMCT), postmortem computed tomography angiography (PMCTA), percutaneous needle biopsy (PNB), postmortem magnetic resonance (PMMR), and traditional autopsy. Imaging and minimally invasive biopsy are potential modalities that might complement or even replace traditional autopsy in diagnosing PFE. Further studies are needed to confirm the sensitivity and specificity of each technique.
\end{abstract}

Keywords: Imaging, minimally invasive biopsy, postmortem computed tomography, postmortem magnetic resonance, pulmonary fat embolism

\section{Pencitraan dan Biopsi Minimal Invasif Pada Diagnosis Postmortem Emboli Lemak Paru}

\begin{abstract}
Abstrak
Beberapa tahun terakhir, teknologi pencitraan dan biopsi minimal invasif semakin berkembang dalam ranah forensik. Penelitian ini bertujuan mengevaluasi peran pencitraan dan biopsi minimal invasif pada diagnosis postmortem dari emboli lemak paru. Pencarian literatur dengan Pubmed, EBSCO-Host, dan ProQuest dilakukan untuk mencari penelitian mengenai diagnosis emboli lemak paru pada postmortem dengan pencitraan postmortem dan biopsi minimal invasif. Lima penelitian diikutsertakan dalam telaah sistematis, dengan metode diagnosis yang dilaporkan dalam penelitian adalah postmortem computed tomography (PMCT), postmortem computed tomography angiography (PMCTA), percutaneous needle biopsy (PNB), postmortem magnetic resonance (PMMR), dan autopsi tradisional. Pencitraan dan biopsi minimal invasif berpotensi melengkapi atau bahkan menggantikan autopsi tradisional dalam mendiagnosis emboli lemak paru. Penelitian lebih lanjut diperlukan untuk mengonfirmasi sensitivitas dan spesifisitas tiap-tiap teknik.
\end{abstract}

Kata kunci: Biopsi minimal invasif, emboli lemak paru, pencitraan, postmortem computed tomography, postmortem magnetic resonance Corresponding author: Gabriella, Faculty of Medicine, Atma Jaya Catholic University of Indonesia, Jakarta, Indonesia, Jl.
Aquamarine Selatan no. 10, Kabupaten Tangerang, Banten, Indonesia, Email: gabriellahamid21@gmail.com 


\section{Introduction}

Fat embolism syndrome is a disease affecting mainly capillaries, particularly on the venous side. Hence, the lung is the most common organ affected in fat embolism syndrome. The manifestations of fat embolism are varied, and thus, the exact pathophysiology of fat embolism is still a controversy. Fat embolism syndrome usually presenting with a delay of 12-72 hours, the classical triad consists of respiratory distress, cerebral signs, and petechiae. These can go unnoticed clinically or may present as an acute fatal event within hours of the inciting injury. There is no specific treatment for FES, but we can do supportive management and prevention or prompt management of complications. Examples include early fixation of long bone fractures within 24 hours, prophylactic corticosteroids, albumin for volume resuscitation, and other measures that can be adapted to the existing symptoms. The incidence of fat embolism and fat embolism syndrome is not known with certainty, as milder forms of fat embolism may not be clinically detectable. With the help of postmortem examination, the incidence increases to $20 \%$. Embolization following major trauma is reported to be a quite common event, while a clinical fat embolization syndrome seems to be a much rarer event. ${ }^{1}$ Fat embolism can be caused by fracture of long bones, injury to adipose tissue which forces fat into damaged blood vessels, injecting oil into circulation, burns, septicemia, natural disease without any trauma, as in sickle cell anemia, diabetes, blood transfusion, or in chronic alcoholic. ${ }^{2}$ Distinguishing antemortem violence with other causes of fat embolism is crucial in forensic settings. Histopathological analysis is currently used for definitive diagnosis of PFE. ${ }^{3}$

In recent years, imaging technologies such as postmortem computed tomography (PMCT), postmortem computed tomography angiography (CTA), multislice computed tomography (MSCT), and postmortem magnetic resonance (PMMR) imaging had been implemented in medicolegal settings. Minimally invasive biopsy has also been gaining importance in this field.

Are imaging and minimally invasive biopsy superior to traditional autopsy in postmortem diagnosis of pulmonary fat embolism cases? This question will be addressed in this systematic review.

\section{Methods}

This systematic review was designed and conducted in accordance with the guideline based on the Preferred Items for Systematic

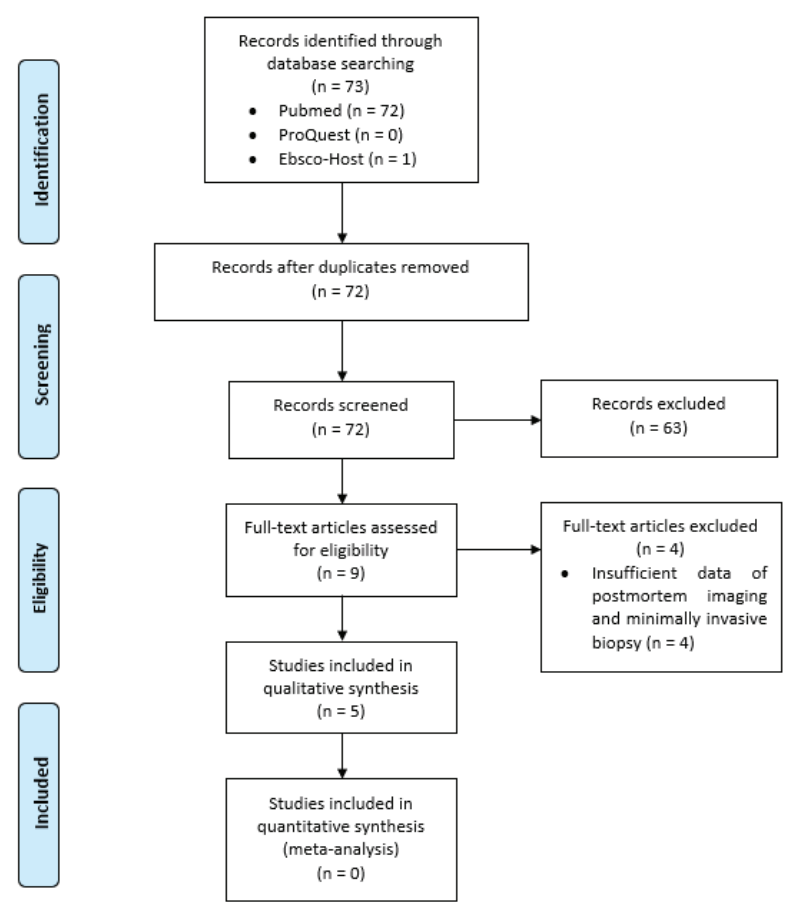

Figure Flow Diagram of Study Selection 
Table 1 Medical Subject Heading Used for Literature Search

\begin{tabular}{|c|c|}
\hline Library & Medical Subject Heading \\
\hline Pubmed & 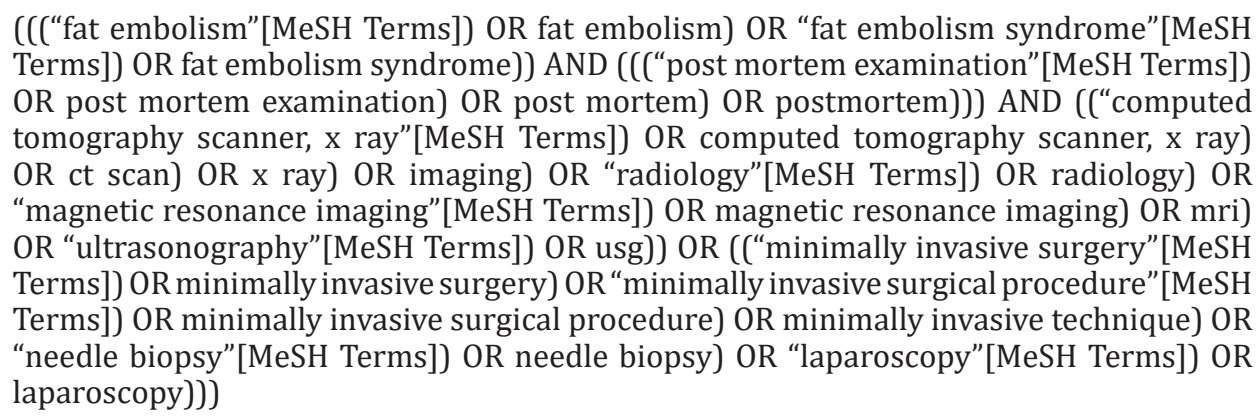 \\
\hline EBSCO-Host & $\begin{array}{l}\text { (TI fat embolism OR AB fat embolism OR TI fat embolism syndrome OR AB fat embolism } \\
\text { syndrome) AND (TI post mortem examination OR AB post mortem examination OR TI } \\
\text { post mortem OR AB post mortem) AND (TI computed tomography scanner, x ray OR } \\
\text { AB computed tomography scanner, x ray OR TI ct scan OR AB ct scan OR TI imaging OR } \\
\text { AB imaging OR TI radiology OR AB radiology OR TI magnetic resonance imaging OR } \\
\text { AB magnetic resonance imaging OR TI mri OR AB mri OR TI ultrasonography OR AB } \\
\text { ultrasonography OR TI usg OR AB usg OR TI minimally invasive surgery OR AB minimally } \\
\text { invasive surgery OR TI minimally invasive surgical procedure OR AB minimally invasive } \\
\text { surgical procedure OR TI minimally invasive techniqueORAB minimally invasivetechnique } \\
\text { OR TI needle biopsy OR AB needle biopsy OR TI laparoscopy AND AB laparoscopy) }\end{array}$ \\
\hline ProQuest & $\begin{array}{l}\text { (ab(fat embolism) OR ti(fat embolism) OR ab(fat embolism syndrome) OR ti(fat embolism } \\
\text { syndrome)) AND (ab(post mortem examination) OR ti(post mortem examination) OR } \\
\text { ab(post mortem) OR ti(post mortem)) AND (ab(computed tomography scanner, x ray) } \\
\text { OR ti(computed tomography scanner, x ray) OR ab(ct scan) OR ti(ct scan) OR ab(imaging) } \\
\text { OR ti(imaging) OR ab(radiology) OR ti(radiology) OR ab(magnetic resonance imaging) } \\
\text { OR ti(magnetic resonance imaging) OR ab(mri) OR ti(mri) OR ab (ultrasonography) } \\
\text { OR ti(ultrasonography) OR ab(usg) OR ti(usg) OR ab(minimally invasive surgery) } \\
\text { OR ti(minimally invasive surgery) OR ab(minimally invasive surgical procedure) } \\
\text { OR ti(minimally invasive surgical procedure) OR ab(minimally invasive technique) } \\
\text { OR ti(minimally invasive technique) OR ab(needle biopsy) OR ti(needle biopsy) OR } \\
\text { ab(laparoscopy) OR ti(laparoscopy)) }\end{array}$ \\
\hline
\end{tabular}

Reviews and Meta-Analysis (PRISMA) statement. We include cross-sectional, cohort, case control, case report, and case series studies. Conversely, review, conference abstract, book section, commentaries or editorial work were excluded. Laboratories and non-human studies, also articles with unavailable full-text, languages other than English, and irrelevant topics were omitted. We included every study with pulmonary fat embolism examined with postmortem imaging and minimally invasive biopsy.

We performed a literature search using several search engines, including Pubmed, EBSCO-Host, and ProQuest by the year of 2021. Studies were identified by six independent authors using medical subject heading listed in Table 1.

All the search outputs were exported to the EndNote X9 software. After duplicates removal, retrieved articles were screened based on their titles and abstracts. Potentially eligible articles were thoroughly assessed in full text using the eligibility criteria described above. Any emerging discrepancies were resolved among the review team.

Included studies were analyzed and the following data was extracted: first author, country of origin, study design, population (age and sex), postmortem examination, and outcomes.

\section{Results}

The study selection is presented in Figure 1 . We conducted a search in PubMed, EBSCO-Host, and ProQuest by the year of 2021. A total of 73 records were identified, from which 72 remained after duplicate removal. Titles and abstracts were screened, leaving 9 potential studies. Full- 


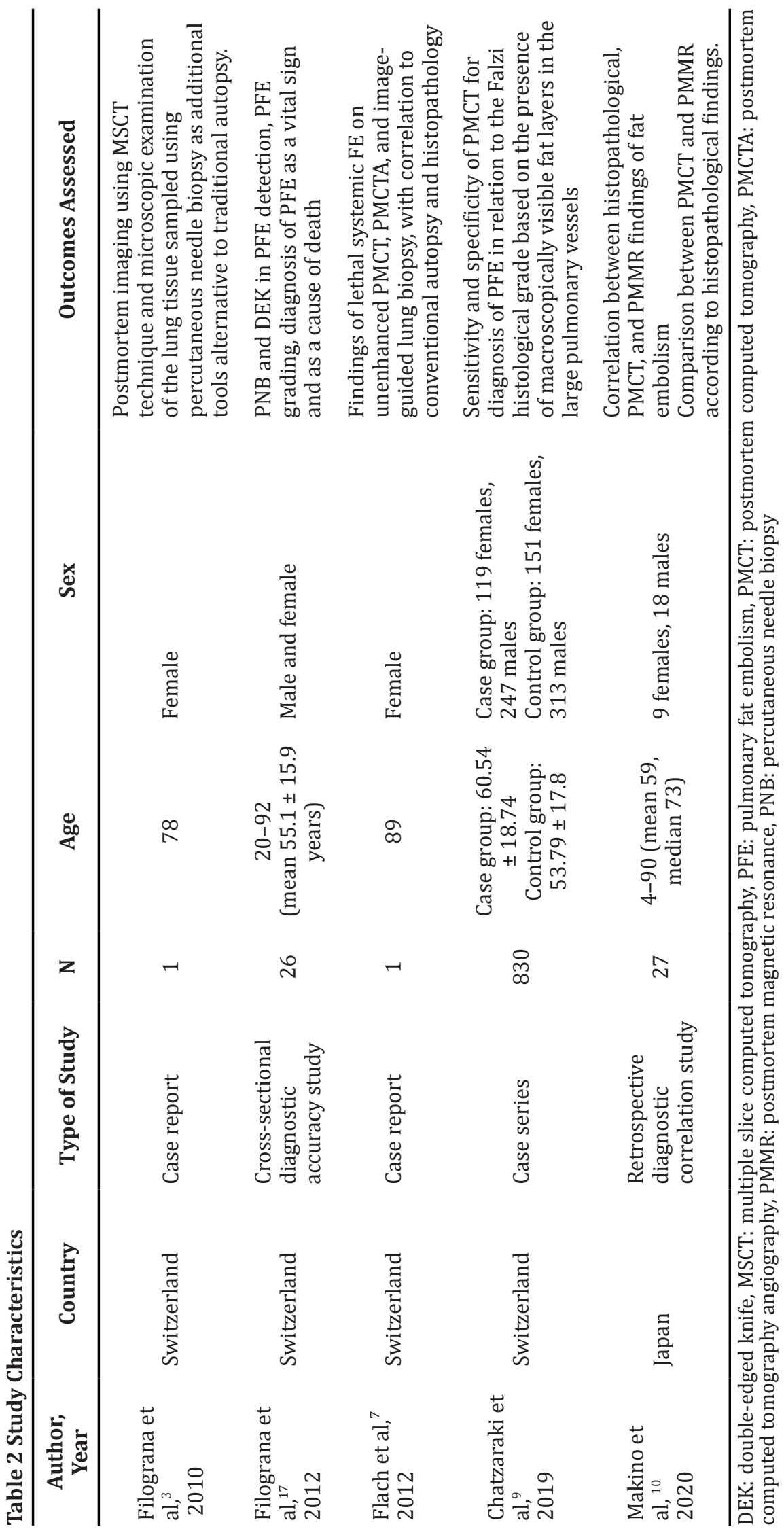




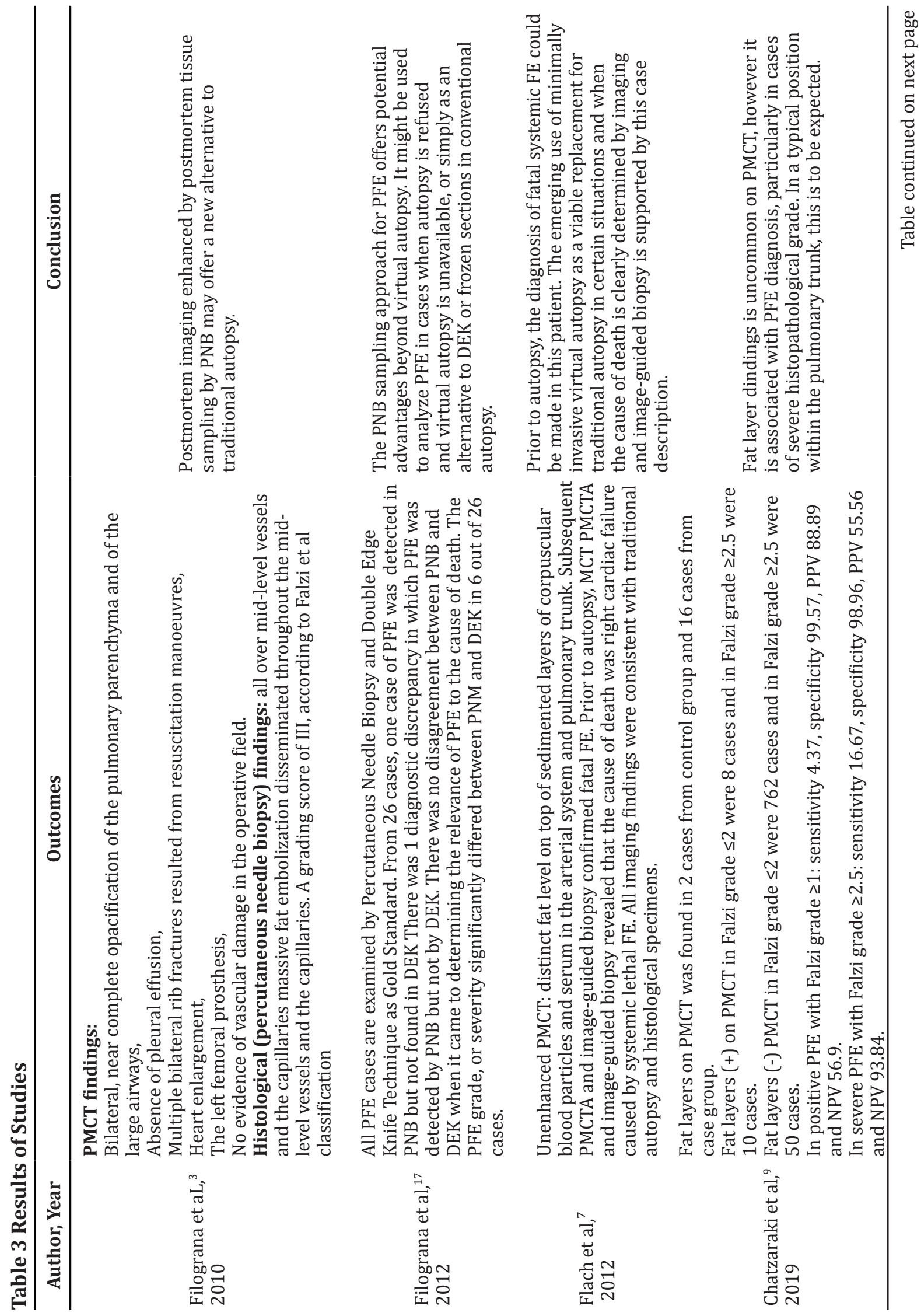




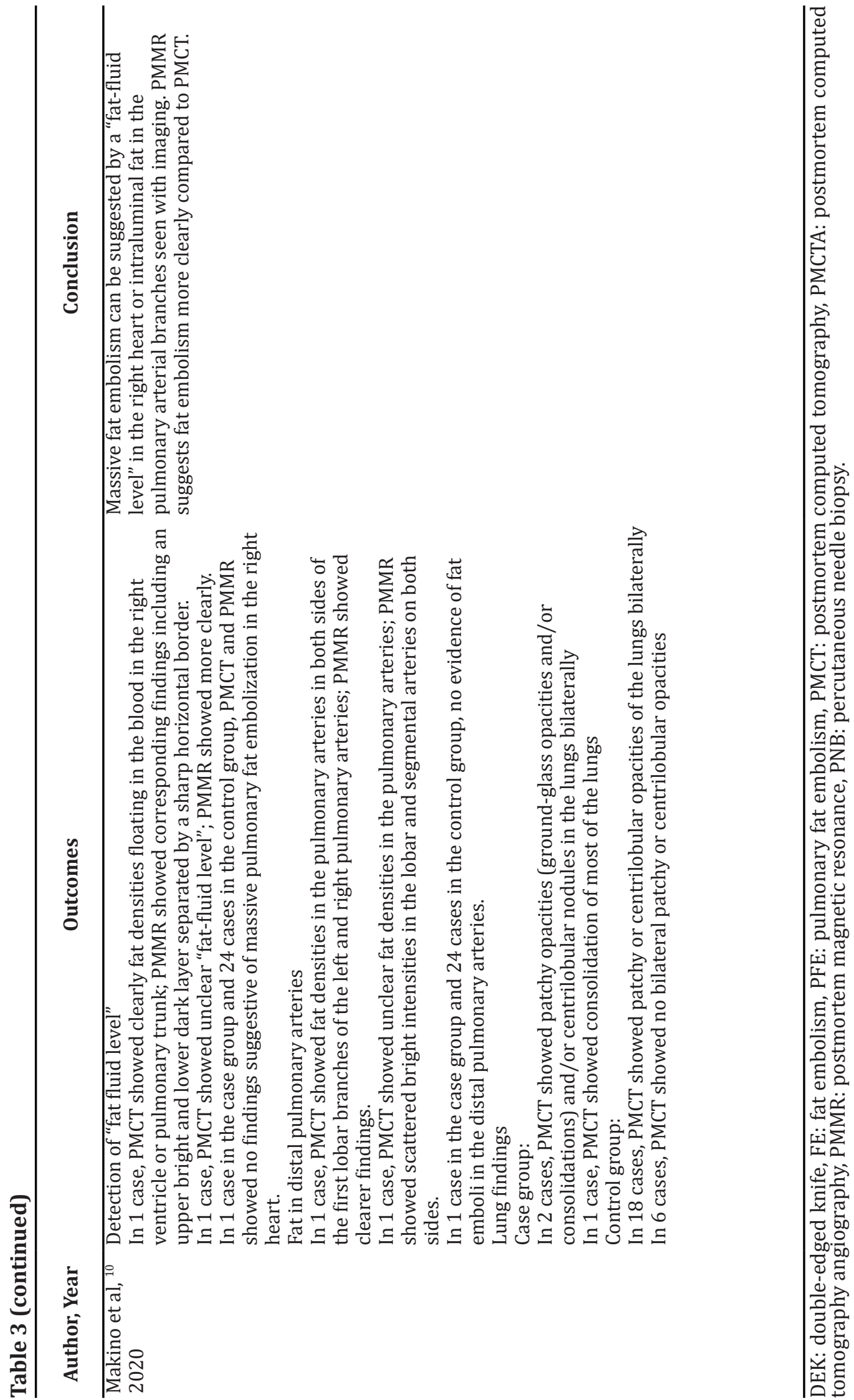


Table 4 Fat Embolism Syndrome Diagnostic Criteria

\begin{tabular}{llll}
\hline \multicolumn{1}{c}{ Major criteria } & & Minor criteria \\
\hline 1. & Petechial rash & 1. & Tachycardia $>120$ \\
2. & $\begin{array}{l}\text { Respiratory } \\
\text { insufficiency }\end{array}$ & 2. & Fever \\
3. $\begin{array}{l}\text { Cerebral } \\
\text { involvement }\end{array}$ & 3. & Retinal changes: fat \\
& 4. & Jaundice \\
& 5. & Renal signs: anuria \\
& 6. & or oliguria \\
& 7. & Anemia \\
& 8. & High erythrocyte \\
& sedimentation rate \\
& 9. & Fat \\
& & macroglobulinemia \\
\hline
\end{tabular}

text paper of each 9 studies was evaluated for eligibility criteria and 4 was excluded due to insufficient data of postmortem imaging and minimally invasive biopsy. The remaining five studies were included in the systematic review. There are five studies included in this systematic review. Table 2 shows details on the selected studies for the systematic review. Most studies included were conducted in Switzerland. There are two case reports, one cross sectional study, one case series, and one retrospective diagnostic correlation study. Four studies evaluating PMCT are Filograna et $\mathrm{al}^{3}$; Flach et $\mathrm{al}^{7}$; Chatzaraki et al. ${ }^{9}$ We also found four studies evaluating biopsy technique, which were conducted by Filograna et $\mathrm{al}^{3}$; Flach et $\mathrm{al}^{7}$; Makino et $\mathrm{al}^{10}$ respectively. In addition, there is one study evaluating PMMR, which was conducted by Makino et al. ${ }^{10}$

We summarize the included studies by the outcome and conclusion as shown in Table 3.

\section{Discussion}

Fat embolism (FE) is the finding of fat globules in the pulmonary or peripheral circulation, otherwise FE syndrome is its manifestations followed by a remarkable insult resulting in triad of respiratory distress, neurologic symptoms and petechial rash. ${ }^{5}$

Diagnostic criteria for fat embolism syndrome according to Gurd et al. are at least one major or four minor criteria as described in Table $4 .{ }^{6}$

Fat embolism often occurs due to major fractures (in particular long bones pelvis or spine) and severe soft tissue damage concomitant to trauma. Furthermore, in general, orthopaedic interference of the intramedullary region consequently lead to fat embolism complication. This procedure contributes to higher intramedullary pressure which enforces the entry of fat and bone marrow into the venous circulation. Among patients with fat embolism, $1-5 \%$ represent fat embolism syndrome, despite the manifestation being commonly asymptomatic. Subsequently, this could be fatal in up to $20 \%$ cases. The distinct pattern of FES sign and symptoms as a sequel of some organs dysfunction (mainly lungs, brain, and skin) denoted by gradual onset predominantly 12-36 $\mathrm{h}$ after the accompanying injury. ${ }^{3}$

As respiratory symptoms is the major clinical presentation of FES, it is reported that within $50 \%$ of patients with FES whereupon turn dyspnoeic, which then require mechanical ventilation due to hypoxemia. The lungs is the initial organ interfered by fat embolism and its risk of fatalities in FE commonly influenced by the volume of the fat that gets through the lungs and capillary bed. These mortality cases of FE involving lungs have been described by two pathophysiology consisting of mechanical and chemical mechanisms. Firstly, in an early mechanical phase, fat droplets derived from the sites of injury, then gain entry to the circulation which further impairs the process of gas exchange by occluding lung capillaries. The latter is associated with chemical pneumonitis, vasculitis and related perivascular haemorrhage and edema, which furthermore results in mechanical obstruction. Both mechanical and chemical effects of FE in the pulmonary system generate acute respiratory distress whereas causing hypoxia that lead to death. ${ }^{3}$

The importance of fat embolism presence during autopsy in determination of related cause of death have remained uncertain. Histopathological analysis is the most commonly applied system by a lot of authors regarding the severity of embolism assessment by quantitative or semi-quantitative methods. However, it is still controversial between the correlation of the quantitative amount of FE and the severity of its clinical presentation. Several authors support the theory of an immediate correlation, in contrast, the others hypothesize that there is a crucial role of unusual reaction to fat in the capillary bed. Nevertheless, whichever the case, diagnosis of death due to FE is a diagnosis of exclusion. The other fatal contributing factors and required correlation of the degree of fat embolism with pre-existing diseases, remarkably cardiorespiratory pathologies should be excluded. ${ }^{3}$ 
LD Yen et al: Imaging and Minimally Invasive Biopsy for Postmortem Pulmonary Fat Embolism Diagnosis: A Systematic Review

Table 5 Falzi Grading of Pulmonary Fat Embolism

\begin{tabular}{lll}
\hline \multicolumn{1}{c}{ Grading Scale } & \multicolumn{1}{c}{ Shape of Emboli } & \multicolumn{1}{c}{ Localization } \\
\hline 0 (no PFE) & (Punctiform) & Sporadic, not in every microscopic field \\
I (light) & Drop-shaped & Sporadic, in every microscopic field \\
II (moderate) & Sausage-shaped or rounded & Multiple, disseminated in every microscopic field \\
III (massive) & Antler-shaped & Numerous everywhere, in every microscopic field \\
\hline
\end{tabular}

Pulmonary fat embolism (PFE) in postmortem computed tomography (PMCT) was found as bilateral, near complete opacification of the pulmonary parenchyma in the study conducted by Filograna et al. $^{3}$ The forensic importance of fat embolism discovered at autopsy in relation to cause of death determination is still an unresolved issue. Many researchers have used quantitative or semi-quantitative approaches to grade the severity of embolism, the most common of which is histological analysis. Nonetheless, the relationship between the amount of FE in the blood and the severity of its clinical symptoms remains a source of debate. ${ }^{3}$

Some researchers believe there is a direct link, while others believe that an individual's aberrant sensitivity to fat in the capillary bed plays a key role. In any instance, FE death can only be diagnosed when other lethal reasons have been ruled out and a mandatory correlation of the degree of fat embolism with pre-existing disorders, particularly cardio-respiratory abnormalities. ${ }^{3}$

In the study performed by Flach et al., ${ }^{7}$ unenhanced pmCT revealed a distinct fat level on top of sedimented layers of corpuscular blood particles and serum in the arterial system and pulmonary trunk. Subsequent pmCTA showed reproducible results, and image-guided biopsy confirmed fatal FE.

In clinical radiology some reports describe the visualization of fat in the pulmonary arteries on computed tomography or transesophageal echocardiography. A patchy ground-glass opacities or consolidations resembling acute respiratory distress syndrome and subpleural centrilobular nodules in the lungs are more frequent findings in fat embolism syndrome. ${ }^{8}$

PMCT done by Chatzaraki et al. showed fat layers based on Falzi grading, 2 in the control group and 16 in the case group. The sensitivity in positive PFE with Falzi grade $\geq 1$ was 4.37, specificity 99.57, PPV 88.89 and NPV 56.9. This shows that the fat layer in PMCT can be used in diagnosing PFE but it is rarely found. Fat layer is specific in determining the severity of PFE, but with more sensitivity. If found, it shows $55.56 \%$ of severe PFE, and negative fat layer 93.84\% showed PFE with Falzi grade $<2$. Fat layered findings on PMCT can also reveal CPR-induced PFE that has no connection to antemortem trauma. In high Falzi grade, determining the severity has similar specificity and slightly higher sensitivity. Fifty five percent of the result shows true positive and $93 \%$ of the result shows true negative in high Falzi grade. ${ }^{9}$

As stated earlier, PMCT conducted by Makino et al. $^{10}$ revealed fat densities that were clearly evident floating in the blood in the right ventricle or pulmonary trunk, displaying a "fat-fluid level" in one of the cases, while one of the other cases also showed fat around the ventricle wall without apparent "fat-fluid level". PMCT also showed fat densities in the pulmonary arteries in two of the cases, although one of them was unclear. Based on these findings, there are two possible signs of fat embolism: the "fat-fluid level" in the right ventricle or pulmonary trunk and fat in the pulmonary arterial branches. In their control subjects, these findings were absent. Their study showed that these findings did not always correspond with the histopathological diagnosis of massive fat embolism, and a negative scan did not rule out massive fat embolism. CT can detect fat based on its density, however it can also miss fats. When combined with other materials that increase the density of the fat, it will result in inaccurate imaging. ${ }^{11}$

Although all of the studies show promising use of PMCT to determine the cause of death in PFE cases, it is still unclear whether PMCT examination is necessary in cases without showing signs of FE syndrome or whether PMCT can be used as a routine forensic practice in the future. A larger sample study is still needed to obtain more specific signs in PMCT imaging.

Percutaneous needle biopsy (PNB) was done in studies done by Filograna et al. in 2010 and 2012, and by Falch et al. ${ }^{7}$ In 2010, a massive fat embolization was found throughout the mid- 
level vessels and capillaries and had a Falzi grade III after stained with Sudan.

In the study demonstrated by Filograna et al., ${ }^{17}$ PFE detection and grading using samples taken with PNB and double-edged knife (DEK) autopsy technique were compared. This study shows no disagreement in detection and diagnosis of PFE, except in diagnosis of 1 case out of 26 . Similarly, there was no disagreement in the determination of the relationship of PFE to the cause of death between PNB and DEK. Although a significant difference of grading was found in 6 cases out of 26, this difference did not affect the ultimate determination of cause of death. According to Filograna et al., this difference might be affected by different operators performing the DEK cuts.

Falch et al. use image-guided PNB and found PFE with grade IV according to Mason and Grade III according to Falzi. This finding were in accordance with histological findings using double-edge knife autopsy.

PNB has several advantages, such as its acceptability, simplicity, and decreased risk of disease transmission compared to complete autopsies. Furthermore, PNB is not as dependent on operator expertise and has a high success rate, especially guided with imaging techniques. ${ }^{12}$ Compared to autopsy, sampling using PNB requires less time, in which around 10 minutes was needed. Autopsy in the other time takes at least 30 minutes. Minimally invasive technique is also beneficial in settings in which autopsy was rejected due to religion and cultural belief.

Some considerations should be made on blind biopsies of the target organ. A study performed by Cox et al. ${ }^{12}$ showed a lower success rate when biopsy was done blindly without guidance of imaging modalities. Without a macroscopic view of the organs, some data important for determining other causes of death might also be missed even with the guidance of imaging. ${ }^{13}$ Moreover, a full minimally invasive autopsy with full body imaging and sampling of all major organs may need more time than autopsy.

In general, MR imaging produces higher quality of images compared to CT scan. However, the use of MR imaging in forensic medicine is still limited. This might be due to the relatively long time and higher cost needed to perform MR imaging. Moreover, there are several factors that may influence the quality of the images produced and render the interpretation; the presence of gas, temperature, and vascular stasis. ${ }^{14}$ Nevertheless, Makino et al. have found that PMMR displayed fat-fluid level and fat in distal pulmonary arteries more clearly than
PMCT. The reason for this is that MR imaging is able to detect the fat resonant frequency more specifically. Additionally, fat-specific techniques can be used to further confirm the presence of fat, such as spectral attenuated inversion recovery (SPAIR) and fast field echo sequences (FFE), as seen in this study. Thus, PMMR might be beneficial in detecting fat-fluid level in cases where PMCT findings of PFE are uncertain.

There are several cases in which PMMR was found to be useful, such as cardiovascular pathologies, internal hemorrhage or fluid accumulation, brain and pulmonary edema, pleural effusion, and neonatal or pediatric death. ${ }^{16}$ To date, studies have investigated the use of PMMR in fat embolism, mainly cerebral fat embolism, and some reported that PMMR has a high sensitivity for such cases. ${ }^{15,16}$ Further studies are still needed to validate the use of PMMR in diagnosing PFE.

Imaging and minimally invasive biopsy are potential modalities that might complement or even replace traditional autopsy in diagnosing PFE. Although in some cases imaging findings do not always correlate with the histopathological diagnosis, they show promising results. Further studies with larger sample sizes are needed to confirm the sensitivity and specificity of each technique, and thus, to support the use of minimally invasive techniques in forensic medicine.

\section{References}

1. George J, George R, Dixit R, Gupta RC, Gupta N. Fat embolism syndrome. Lung India. 2013;30(1):47-53.

2. Biswas G. Review of forensic medicine and toxicology. New Delhi: Jaypee Brothers Medical Publishers; 2015.

3. Filograna L, Bolliger SA, Spendlove D, Schön C, Flach PM, Thali MJ. Diagnosis of fatal pulmonary fat embolism with minimally invasive virtual autopsy and post-mortem biopsy. Legal Med. 2010;12(5):233-7.

4. Moskała A, Woźniak K, Kluza P, Romaszko $\mathrm{K}$, Lopatin $\mathrm{O}$. The importance of postmortem computed tomography (PMCT) in confrontation with conventional forensic autopsy of victims of motorcycle accidents. Leg Med (Tokyo). 2016;18:25-30.

5. Eriksson EA, Pellegrini DC, Vanderkolk WE, Minshall CT, Fakhry SM, Cohle SD. Incidence of pulmonary fat embolism at autopsy: An undiagnosed epidemic. J Trauma. 2011;71: 
312-5.

6. Gurd AR, Wilson RI. The fat embolism syndrome. J Bone Joint Surg Br. 1974;56$\mathrm{B}(3): 408-16$.

7. Flach PM, Ross SG, Bolliger SA, Ampanozi G, Hatch GM, Schön C, et al. Massive systemic fat embolism detected by postmortem imaging and biopsy. J Forensic Sci. 2012;57(5):137680.

8. Unal E, Balci S, Atceken Z, Akpinar E, Ariyurek OM. Nonthrombotic pulmonary artery embolism: imaging findings and review of the literature. Am J Roentgenol. 2017;208:112

9. Chatzaraki V, Heimer J, Thali MJ, Ampanozi G, Schweitzer W. Approaching pulmonary fat embolism on postmortem computed tomography. Int J Legal Med. 2019;133(6):1879-87.

10. Makino Y, Kojima M, Yoshida M, Motomura A, Inokuchi G, Chiba F, et al. Postmortem CT and MRI findings of massive fat embolism. Int J Legal Med. 2020;134(2):669-78.

11. Morikawa K, Hyodoh $\mathrm{H}$, Matoba K, Mizuo K, Okazaki S, Watanabe S. Time-related change evaluation of the cerebrospinal fluid using postmortem CT. Legal Med. 2016;22:30-5.

12. Cox J, Lukande R, Kalungi $S$, Van de Vijver K, Van Marck E, Nelson A, et al. Practice of percutaneous needle autopsy; a descriptive study reporting experiences from Uganda. BMC Clinical Pathol. 2014;14(1):44.
13. Bolliger SA, Filograna L, Spendlove D, Thali MJ, Dirnhofer S, Ross S. Postmortem imagingguided biopsy as an adjuvant to minimally invasive autopsy with CT and postmortem angiography: a feasibility study. AJR Am J Roentgenol. 2010;195(5):1051-6.

14. Grabherr S, Egger C, Vilarino R, Campana L, Jotterand M, Dedouit F. Modern post-mortem imaging: an update on recent developments. Forensic Sci Res. 2017;2(2):52-64.

15. Newbigin K, Souza CA, Torres C, Marchiori E, Gupta A, Inacio J, et al. Fat embolism syndrome: state-of-the-art review focused on pulmonary imaging findings. Respir Med. 2016;113:93-100.

16. Zaitsu Y, Terae S, Kudo K, Tha KK, Hayakawa M, Fujima N, et al. Susceptibility-weighted imaging of cerebral fat embolism. J Comput Assist Tomogr. 2010;34(1):107-12.

17. Filograna L, Bolliger SA, Kneubuehl B, Jackowski C, Hatch GM, Thali MJ. A minimally invasive technique for the detection and analysis of pulmonary fat embolism: a feasibility study. J Forensic Sci. 2012;57(5):1329-35.

18. Neri M, Riezzo I, Dambrosio M, Pomara C, Turillazzi E, Fineschi V. CD61 and fibrinogen immunohistochemical study to improve the post-mortem diagnosis in a fat embolism syndrome clinically demonstrated by transesophageal echocardiography. Forensic Sci Int. 2010;202(1-3):e13-7. 